\begin{tabular}{|c|c|}
\hline $\begin{array}{l}J U L \\
5 T A=4\end{array}$ & 1. EDT 619468 \\
\hline
\end{tabular}

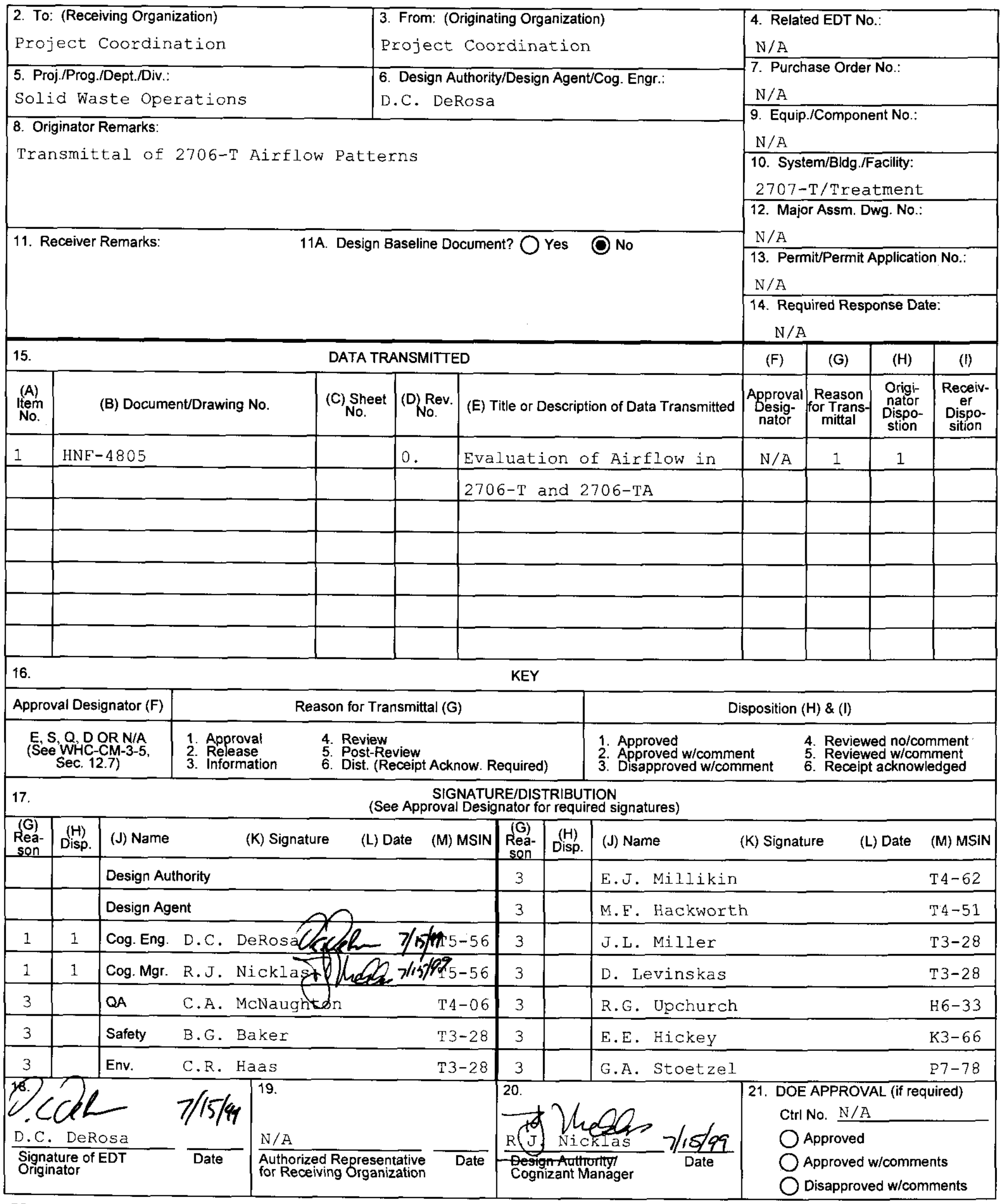




\title{
Evaluation of Airflow Patterns in 2706-T and 2706-TA
}

\author{
David C. DeRosa \\ Waste Management Federal Services of Hanford, Inc, \\ Richland, WA 99352 \\ U.S. Department of Energy Contract DE-AC06-96RL13200

$\begin{array}{lll}\text { EDT/ECN: } 61498 & \text { UC: } 2000 \\ \text { Org Code: } & 32900 & \text { Charge Code: } 101645 \\ \text { B\&R Code: } & \text { EW3130020 } & \text { Total Pages: } 18\end{array}$

Key Words: Airflow evaluation, 2706-T, CAM placement

Abstract: The purpose of this study was to evaluate the adequacy of the current placement of fixed head air samplers and continuous air monitors (CAMs) in the 2706-T and 2706-TA Complex. The airflow study consisted of 6 configurations of facility HVAC and HEPA filtration equipment to determine impacts on CAM location. The results of this study provide recommendations based on guidance in DOE G 411.1-8 and NUREG-1400 for placement of fixed head air samplers or CAMs within 2706-T and 2706-TA

TRADEMARK DISCLAIMER. Reference herein to any specific commercial product, process, or service by trade name, trademark, manufacturer, or otherwise, does not necessarily constitute or imply its endorsement, recommendation, or favoring by the United States Government or any agency thereof or its contractors or subcontractors.

Printed in the United States of America. To obtain copies of this document, contact: Document Control Services, P.O. Box 950, Mailstop H6-08, Richland WA 99352, Phone (509) 372-2420; Fax (509) 376-4989.
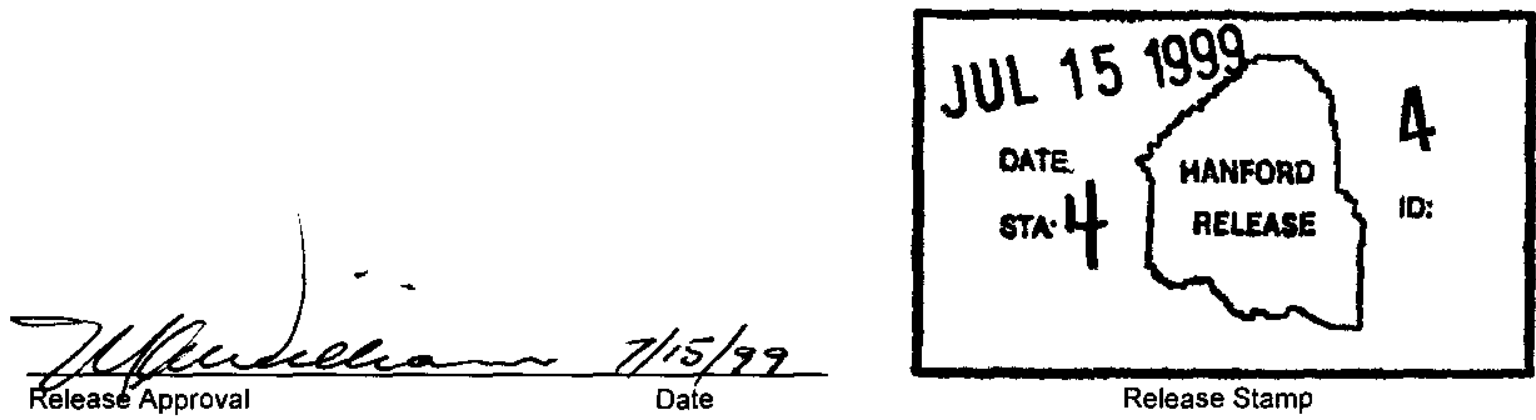

Release Stamp 
EVALUATION OF AIRFLOW PATTERNS IN 2706-T AND 2706-TA

\author{
E. E. Hickey \\ G. A. Stoetzel \\ July 14, 1999 \\ Pacific Northwest National Laboratory \\ Richland, Washington 99352
}




\section{Introduction}

For more than 10 years, Pacific Northwest National Laboratory (PNNL) has provided technical support to Hanford contractors for the purpose of evaluating the adequacy of air sampling and monitoring locations at selected work areas. Work areas within PUREX, N-Reactor, Plutonium Finishing Plant (PFP), B-Plant, 224-T, 222-S, K-East Basin, 105KW Fuel Storage Basin, the Waste Receiving and Processing Facility, and other waste management facilities have been evaluated. Smoke testing was used to determine airflow patterns in the work areas and provided the basis for recommendations on air sampling and monitoring equipment placement.

The objective of this work was to perform qualitative airflow studies in 2706-T and 2706-TA using smoke testing. Results of the studies will verify air sampling equipment placement or provide recommendations for modified placement of equipment. The studies were conducted to satisfy the requirements of the Hanford Site Radiological Control Manual, Section 551.4 and 555.4 which reflect the requirements in 10 CFR 835 . The studies were conducted using guidance in DOE Air Monitoring Guide, DOE G 441.1-8 (DOE 1999). The DOE G 441.1-8 recommends using the methods described in NUREG-1400 (NRC 1993), Air Sampling in the Workplace, for performing airflow pattern studies.

\section{Methods}

Prior to conducting the airflow studies, PNNL staff toured the 2706 Complex to obtain information on air sampling and monitoring equipment, locations of sumps and air spargers, future greenhouses, and the type of work performed in the work areas including potential airborne radioactive material release points. Discussions were held with cognizant facility personnel to obtain information on the work operations, types or radioactive material and the status of the ventilation systems.

Using the guidance in the DOE G 441.1-8 (DOE 1999) and NUREG-1400 (NRC 1993), air flow patterns were characterized using a combination of smoke candles manufactured by Superior Signal Corporation which produce about $4000 \mathrm{ft}^{3}\left(113 \mathrm{~m}^{3}\right)$ of aerosol in 60 seconds and smoke cartridges, manufactured by the Bramec Corporation which produce about $150 \mathrm{ft}^{3}\left(4.2 \mathrm{~m}^{3}\right)$ of aerosol in 45 seconds. Air velocity measurements, using a hot-wire anemometer, were taken at selected locations in the work areas to further define airflow characteristics.

\section{Air Flow Study Results}

The purpose of this study was to evaluate the adequacy of the current placement of fixed head air samplers and continuous air monitors (CAMs) in the 2706-T and 2706-TA Complex. The configurations used in the study were defined in the Statement of Work, "Low Level Decontamination/Repackaging Facility 2706-T Airflow Study", Revision 4 dated May 17, 1999. The study was performed using the Work Plan prepared by PNNL, which was signed and approved by Waste Management Hanford. The airflow studies were conducted on June 16, 1999. 
Airflow patterns in the work areas are illustrated in Figures 1 through 6. Verbal descriptions of airflow patterns for individual work areas are found below. Air velocity measurements in linear $\mathrm{ft} / \mathrm{min}(\mathrm{lfm})$ were made at selected locations in 2706-T and 2706-TA using a calibrated hot-wire anemometer (TSI Model 1640). These measurements provided additional information on airflow and were recorded on the Figures.

The airflow patterns are applicable to situations where there is no worker activity in 2706-T and 2706-TA. During work activities, airflow patterns could vary, particularly in the localized area around a worker who is actively moving.

Airflow patterns in 2706- $\mathrm{T}$ and 2706-TA were determined for six ventilation configurations described below.

Configuration A: Airflow testing in 2706-T with the following equipment operational: 2706-T ACT 1 ventilation system operational (in accordance with DO060-014). The four fan coil units within 2706-T were operational. All exterior doors closed. The air spargers in the railroad pit sump were operational.

Configuration B: Airflow testing in 2706-T with the following equipment operational: 2706-T ACT 1 ventilation system operational (in accordance with DO060-014). The four fan coil units within 2706-T were off. All exterior doors closed. The air spargers in the railroad pit sump were off.

Configuration C: Airflow testing in 2706-TA with the following equipment operational: 2706-TA ACT 2 Ventilation system operational (in accordance with DO060-015). The three fan coil units within 2706-TA were operational. All exterior doors closed. The air spargers in the sump were operational.

Configuration D: Airflow testing in 2706-TA with the following equipment operational: 2706-TA ACT 2 ventilation system operational (in accordance with DO060-015). The three fan coil units within 2706-TA were off. All exterior doors closed. The air spargers in the sump were off.

Configuration E: Airflow testing in 2706-T and 2706-TA with the following equipment operational: 2706-T ACT 1 Ventilation and 2706-TA ACT 2 Ventilation systems operational (in accordance with DO-060-014 and DO-060-015). The four fan coil units within 2706-T and three fan coil units within 2706TA were operational. All exterior doors closed, and the rollup doors between 2706-T and 2706-TA were open. All air spargers were off. 
Configuration F: Airflow testing in 2706-T and 2706-TA with the following equipment operational: 2706-T ACT 1 Ventilation and 2706-TA ACT 2 Ventilation systems operational (in accordance with DO-060-014 and DO-060-015). The four fan coil units within 2706-T and three fan coil units within 2706TA were off. All exterior doors closed, and the rollup doors between 2706-T and 2706-TA were open. All air spargers were off.

The following provides verbal descriptions of the observed airflow patterns. Figures 1 through 6 show these observations pictorially.

Configuration A: Airflow testing in 2706-T with the following equipment operational: 2706-T ACT 1 ventilation system operational (in accordance with DO060-014). The four fan coil units within 2706-T were operational. All exterior doors closed. The air spargers in the railroad pit sump were operational (See Figure 1).

- Candle \#1 was lit at the east end of the rail pit in front of FCU \#2. The smoke aerosol flowed to the east where it encountered airflow out of FCU \#2 and was directed to the north. In the northeast corner of the room, the aerosol encountered the airflow out of FCU \#3 and was directed to the west down the north side of 2706-T. It then dispersed throughout 2706-T. The aerosol cleared through the ceiling exhaust vents. No aerosol was observed going into the rail pit sump.

- Candle \#2 was lit approximately in the center of the rail pit. On the north side of 2706-T, the smoke aerosol was directed to the south by FCU \#4 then up the south wall. The aerosol was then distributed evenly on the south side of 2706-T. From the south side of 2706-T, the smoke aerosol was observed traveling north at elevated levels and dissipated throughout 2706-T about evenly.

- Candle \#3 was lit in front of FCU \#1. The smoke aerosol was drawn into the bottom air inlet of FCU \#1 and then blown out the FCU \#1 vent to the north. The aerosol then dispersed evenly throughout $2706-\mathrm{T}$.

- Candle \#4 was lit near the drum storage area on the north side of 2706-T. The smoke aerosol swirled in the northwest corner, then mixed rapidly and dispersed throughout 2706-T. The aerosol exhausted through the four exhaust vents located on the ceiling.

- Cartridge \#5 was lit near the east end of the rail pit in front of FCU \#2 in the same location as Candle \#1. The same airflow pattern was observed as for Candle \#1 and no aerosol was observed to be drawn into the rail pit sump

- Cartridge \#6 was lit in the west central part of the rail pit. The smoke aerosol drifted towards 
FCU \#1 (no aerosol was drawn into the rail pit sump).

- Cartridge \#7 was lit near the drum storage area. The smoke aerosol was directed to the west by the airflow from FCA \#3. Aerosol rose up the rollup door on the west end of 2706-T and then dispersed throughout 2706-T.

Configuration B: Airflow testing in 2706-T with the following equipment operational: 2706-T ACT 1 ventilation system operational (in accordance with DO060-014). The four fan coil units within 2706-T were off. All exterior doors closed. The air spargers in the railroad pit sump were off. (See Figure 2)

- Candle \#1 was lit in front of FCU \#2. The smoke aerosol rose and drifted slowly throughout the southeast corner of 2706-T. The airflow was very stagnant. Clearance of the aerosol was very slow and the aerosol was observed to sink after a few minutes. Generally, for this configuration there was no observable directional flow.

- Cartridge \#2 was lit in front of FCU \#2 on grating over the rail pit sump in the same location as Candle \#1. The smoke aerosol rose and drifted slowly towards FCU \#2. No aerosol was observed flowing into rail pit sump.

- Cartridge \#3 was lit in the drum area. Smoke drifted slowly to the south over the contamination area.

Configuration C: Airflow testing in 2706-TA with the following equipment operational: 2706-TA ACT 2 Ventilation system operational (in accordance with DO060-015). The three fan coil units within 2706-TA were operational. All exterior doors closed. The air spargers in the sump were operational. (See Figure 3)

- Candle \#1 was lit in front of FCU \#6. The smoke aerosol drifted to the northeast toward the floor-level exhausters along the north wall. The aerosol dispersing throughout 2706-TA within approximately 5 minutes.

- Candle \#2 was lit in the northwest corner of 2706-TA in front of the small rollup door. The smoke aerosol rose and drifted to the east along the north wall. Aerosol at the floor-level was observed exhausting into the floor-level exhausters on the north wall. Once elevated, the smoke aerosol drifted to the south and mixed throughout 2706-TA. After several minutes, there was a stagnant layer of aerosol observed about 15-20 ft off the floor.

- Candle \# 3 was lit over the sump in front of FCU \#7. The smoke aerosol moved toward FCU \#7. Much of the aerosol was observed exhausting through the center exhauster on the north wall. The remaining aerosol stayed on the north side of 2706-TA exhausting into floor-level exhausters on the north wall. 
- Candle \#4 was lit in the northeast corner of 2706-TA near the small rollup door into 2706-T. The smoke aerosol dispersed in the northeast corner of 2706-TA and drifted to the west exhausting into floor-level exhausters located along the north wall. Several stratified smoke layers formed after several minutes - one was located about $6-10 \mathrm{ft}$ off the floor and another about $15 \mathrm{ft}$ to the ceiling.

- Candle \#5 was lit on the rail tracks in front of FCU \#5. The smoke aerosol rose and drifted to the northwest towards the floor-level exhausters along the north wall. The smoke aerosol formed a stratified layer at about 4 to $12 \mathrm{ft}$ off the floor.

- Cartridge \#6 was lit on the sump grating over the sparger. The smoke aerosol went directly into the center-most exhauster (next to the exhauster with the CAM).

- Cartridge \#7 was lit on the sump grating closer to north wall. The smoke aerosol went primarily into the exhauster behind the CAM unit.

Configuration D: Airflow testing in 2706-TA with the following equipment operational: 2706-TA ACT 2 ventilation system operational (in accordance with DO060-015). The three fan coil units within 2706-TA were off. All exterior doors closed. The air spargers in the sump were off. (See Figure 4)

- Candle \#1 was lit in front of FCU \#5. The smoke aerosol rose and drifted towards the floorlevel exhausters located along the north wall. Most of the aerosol stayed in the east end of 2706-TA. The aerosol dissipated slowly.

- Candle \#2 was lit in front of FCU \#6. The smoke aerosol rose and drifted to the northeast into the floor-level exhausters on the north wall. There was a stratified layer of smoke observed about $20 \mathrm{ft}$ off the floor.

- Candle \#3 was located on the sump grating over the sparger. The smoke aerosol rose and drifted to the northeast - some of the aerosol when into floor-level exhausters initially. Most of the aerosol was elevated traveling up the north wall. Near the ceiling the aerosol was noted drifting to the south. Most of the smoke aerosol stayed high (greater than $10 \mathrm{ft}$ ).

- Cartridge \#4 was located on the sump grating closer to the north wall (near the CAM). The smoke aerosol went directly into exhaust vent behind the CAM.

- Cartridge \#5 was located on the sump grating over the sparger in the same location as Candle \#3. The smoke aerosol went directly into the center exhaust vent next to FCU \#7. 
Configuration E: Airflow testing in 2706-T and 2706-TA with the following equipment operational: 2706-T ACT 1 Ventilation and 2706-TA ACT 2 Ventilation systems operational (in accordance with DO-060-014 and DO-060-015). The four fan coil units within 2706-T and three fan coil units within 27,06TA were operational. All exterior doors closed, and the rollup doors between 2706-T and 2706-TA were open. All air spargers were off. (See Figure 5)

- Candle \#1 was lit in the center of the large rollup door between 2706-T and 2706-TA. Most of smoke aerosol traveled into 2706-T. At floor-level, a small portion was drawn into the air inlet of FCU \#5 in 2706-TA. Smoke aerosol in 2706-T was directed to the north by FCU \#1.

- Candle \#2 was lit in the center of the small rollup door between 2706-T and 2706-TA. The smoke aerosol flowed rapidly at floor level to the west into 2706-TA. Airflow from FCU \#3 in 2706-T caused the floor level flow into 2706-TA. Some of the aerosol in 2706-TA exhausted into the exhausters located on the north wall; however, most of the aerosol continued to west wall where it rose and was dispersed throughout 2706-TA.

- Cartridge \#3 was lit on the 2706-TA sump grating close to the north wall (near the CAM). The smoke aerosol was directed to the west - there was no observable flow into the exhausters located along the north wall

- Cartridge \#4 was lit in the south central portion of 2706-TA. The smoke aerosol drifted to the east very slowly.

Configuration F: $\quad$ Airflow testing in 2706-T and 2706-TA with the following equipment operational: 2706-T ACT 1 Ventilation and 2706-TA ACT 2 Ventilation systems operational (in accordance with DO-060-014 and DO-060-015). The four fan coil units within 2706-T and three fan coil units within 2706TA were off. All exterior doors closed, and the rollup doors between 2706-T and 2706-TA were open. All air spargers were off. (See Figure 6)

- Candle \#1 was lit in the center of the small rollup door between 2706-T and 2706-TA. At floor level (0-5 ft) the smoke aerosol flowed into 2706-TA and into the exhausters located along the north wall. Elevated flow was into 2706-T and a slow drift down the north wall and throughout 2706-T. Most of aerosol did go into 2706-T and that which went into TA was quickly exhausted into exhausters along the north wall of 2706-TA.

- Candle \#2 was lit in the center of the large rollup door between 2706-T and 2706-TA. Similar to the small rollup door - the floor-level flow was into 2706-TA and the elevated flow was into 2706-T. There was a strong floor-level into 2706-TA through the large rollup door as evidenced by a large volume of smoke in 2706-TA. The aerosol in TA flowed toward the north wall and into the exhausters along the north wall. Elevated flow into 2706-T was to the 
east dispersing throughout 2706-T.

- Cartridge \#3 was lit in the center of the large rollup door between 2706-T and 2706-TA. The smoke aerosol flowed into 2706-TA at floor level.

\section{Discussion}

Air velocity measurements were made for each of the six configurations (See Figures 1 through 6 for locations and measurement values). The velocity of the air and the airflow patterns were significantly impacted by the fan coil units being on or off and the bay doors between 2706-T and 2706-TA being opened. When the fan coil units were off, the air was very stagnant, with little movement and longer clearance times. Operation of the spargers had no impact on the direction of the airflow or the clearance times.

Clearance times were difficult to evaluate. Generally about 5 minutes were allowed to elapse between smoke aerosol releases. After 5 minutes there was still a visible haze present for smoke aerosol releases for all the configurations. In an effort to complete the airflow testing in a timely manner, time for complete dissipation of the smoke aerosol was not allowed. Based on the last smoke aerosol released for each configuration, clearance times (no haze visible) were on the order of 15-20 minutes.

The following summarizes the observations on the impacts from the various configurations that were tested. General conclusions are provided here and the specific recommendations for changes to air monitoring and sampling equipment placement can be found in Section V, Recommendations.

\section{6-T (Fan Coil Units ON versus OFF)}

- Spargers had no effect on airflow.

- There was no noticeable airflow into the rail pit sump area. All smoke aerosol appeared to exhaust through the exhausters located on the ceiling.

- In contrast to 2706-TA, no stratified smoke aerosol layers were noted in 2706-T. This is attributed to presence of the ceiling exhaust vents in 2706-T, which draws airflow upward not allowing stratified layers to form.

- With the fan coil units off airflow was very stagnant as shown by the low velocity readings $(15-25 \mathrm{ft} / \mathrm{min})$ compared to 80 to $>600 \mathrm{ft} / \mathrm{min}$ with the fan coil units operating.

- With the fan coil units operating, FCU \#3 had the most impact on airflow directing airflow rapidly down the north wall in a westerly direction.

- The following observations apply to CAM placement:

- With the fan coil units off, the CAMs are adequate in their current location to monitor an upset condition in the drum storage area. An upset condition in the contamination area (rail pit area) would be better monitored if the CAMs could be relocated closer to the contamination area.

- With the fan coil units on, currently the CAMs are impacted by the airflow from FCU \#3. 
For the drum storage area, the CAMs would be better placed in the northwest corner of the room. For the rail pit area, the CAMs would be better placed closer to the contamination area.

\section{6-TA (Fan Coil Units ON versus OFF)}

- Sparger had no effect on airflow.

- General airflow in the facility was to the north wall exhausting into the five floor-level exhausters. FCUs \#5 and \#6 hastened the northerly flow when operating. FCU \#7 caused turbulence in the general area along the north wall.

- With the fan coil units off airflow was very stagnant as shown by the low velocity readings (30-35 ft/min) compared to 10 to $350 \mathrm{ft} / \mathrm{min}$ with the fan coil units operating.

- Stratified smoke aerosol layers were observed in the room whether the fan coil units were on or off. Formation of these layers may be a result of different air temperature layers, which are sometimes observed in rooms with high ceilings (NRC 1993).

- The following observations apply to air sampler and monitor placement:

- The fixed-location air sampler located to the east of the HVAC sump appears to be positioned adequately as airflow from the sump would be drawn into the bottom of FCU \#5 and should be drawn past this sampler.

- The beta CAM located in front of second exhauster should be moved to the center exhauster to better monitor any releases from the sump area.

\section{6-T/2706-TA (Rollup doors open with fan coil units ON versus OFF)}

- The airflow was not always from 2706-TA into 2706-T as would be expected from the fact that 2706-T is at a more negative pressure.

- With fan coil units on, there was a strong floor-level flow into 2706-TA through the small rollup door caused by FCU \#3 located at the east end of 2706-T. Air flowed rapidly down the north side of 2706-TA at floor-level. Airflow was primarily into 2706-T through the large rollup door.

- With fan coil units off, floor-level airflow was into 2706-TA through both the small and large rollup doors. The floor-level flow was directed towards the exhausters located at floor level along the north wall of 2706-TA.

- The following observations apply to air sampler and monitor placement in 2706-TA:

- The fixed-location air sampler located to the east of the HVAC sump in 2706-TA appears to be positioned adequately as airflow from the sump would be drawn into the bottom of FCU \#5 and should be drawn past this sampler.

- For the situation with the fan coil units off, the beta CAM in 2706-TA, located in front of second exhauster, should be moved to the center exhauster to better monitor any releases from the sump area.

- For the situation with the fan coil units on, the beta CAM in 2706-TA (located in front of second exhauster) would not monitor any release from the sump area. Any releases would be directed toward the west end of the room. The CAM would be better placed a the west end of the room. 
- The following observations apply to CAM placement in 2706-T:

- With the fan coil units off, the CAMs are adequate in their current location to monitor an upset condition in the drum storage area. An upset condition in the contamination area (rail pit area) would be better monitored if the CAMs could be relocated closer to the contamination area.

- With the fan coil units on, currently the CAMs are impacted by the airflow from FCU \#3. For the drum storage area, the CAMs would be better placed in the northwest corner of the room. For the rail pit area, the CAMs would be better placed closer to the contamination area.

\section{Recommendations}

The need for use of CAMs in 2706-T and 2706-TA should be reevaluated based on requirements for air monitoring in 10 CFR 835 and the guidance in DOE G441.1-8. If the CAMs are still required, the Recommendations 1 and 2 are given for CAM locations. If CAMs are not required for either 2706-T or 2706-TA, than the CAMs should be replaced with air samplers in the designated locations.

1. In 2706-T, the beta CAM and alpha CAM located east of FCU \#4 should be relocated to the west side of FCU \#4 (see Figure 7). The basis for this recommendation is to reduce the influence of air movement from FCU \#3 to and to provide better coverage of the drum storage area.

2. In 2706-TA, the CAM should be relocated to the center exhauster (see Figure 7). The basis for this recommendation is to provide better coverage for releases from greenhouses that may be located in 2706-TA or releases from the sump. Fixed head samplers should be located on the two exhausters on either side of the relocated CAM. Since the airflow is extremely variable based on the operation of the fan coil units, this will help ensure that releases from either the west or east side of 2706-TA will be detected.

3. Job specific monitoring is necessary for all tasks with a potential for airborne releases since the airflow patterns in 2706-T and 2706-TA are quite variable. The samplers should be placed as close to the workers as practical, and downwind of the potential release point.

\section{References}

U. S. Department of Energy (DOE). 1999. Air Monitoring Guide. DOE G 441.1-8. March 1999. U. S. Department of Energy, Washington, DC.

U. S. Nuclear Regulatory Commission (NRC). 1993. Air Sampling in the Workplace. NUREG1400. September 1993. Office of Nuclear Regulatory Research, U. S. Nuclear Regulatory Commission, Washington, DC. 


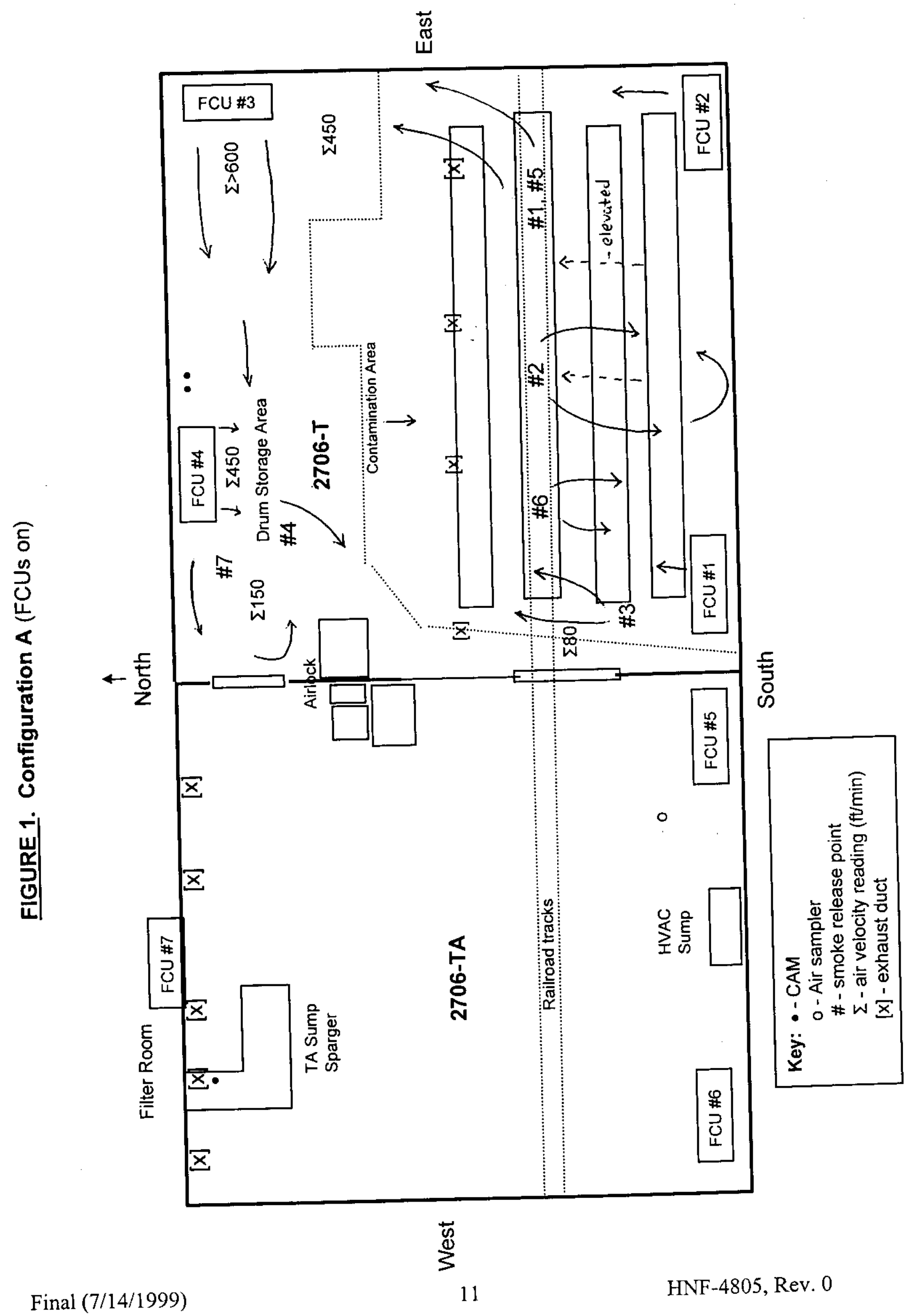


FIGURE 2. Configuration B (FCUs off)

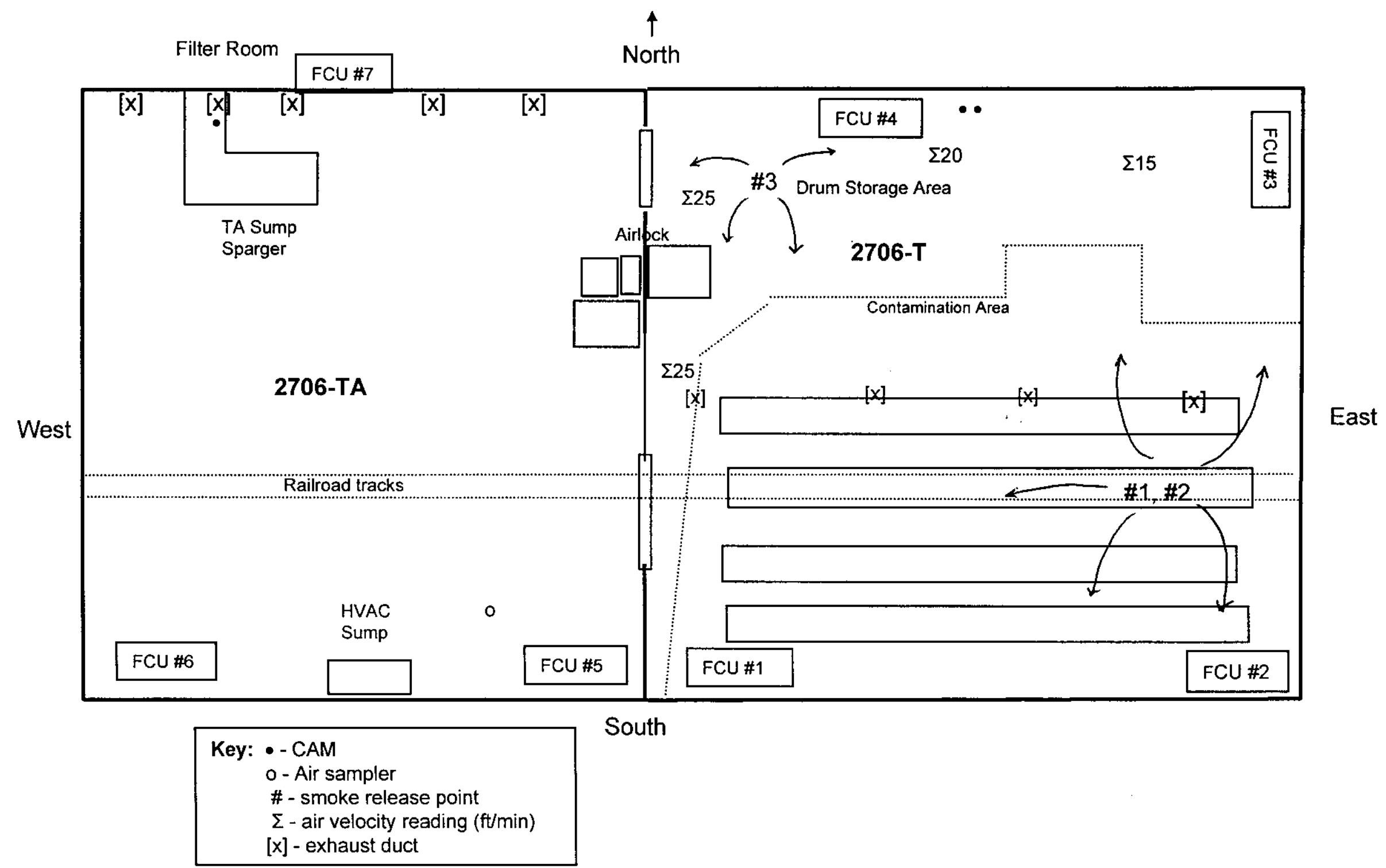




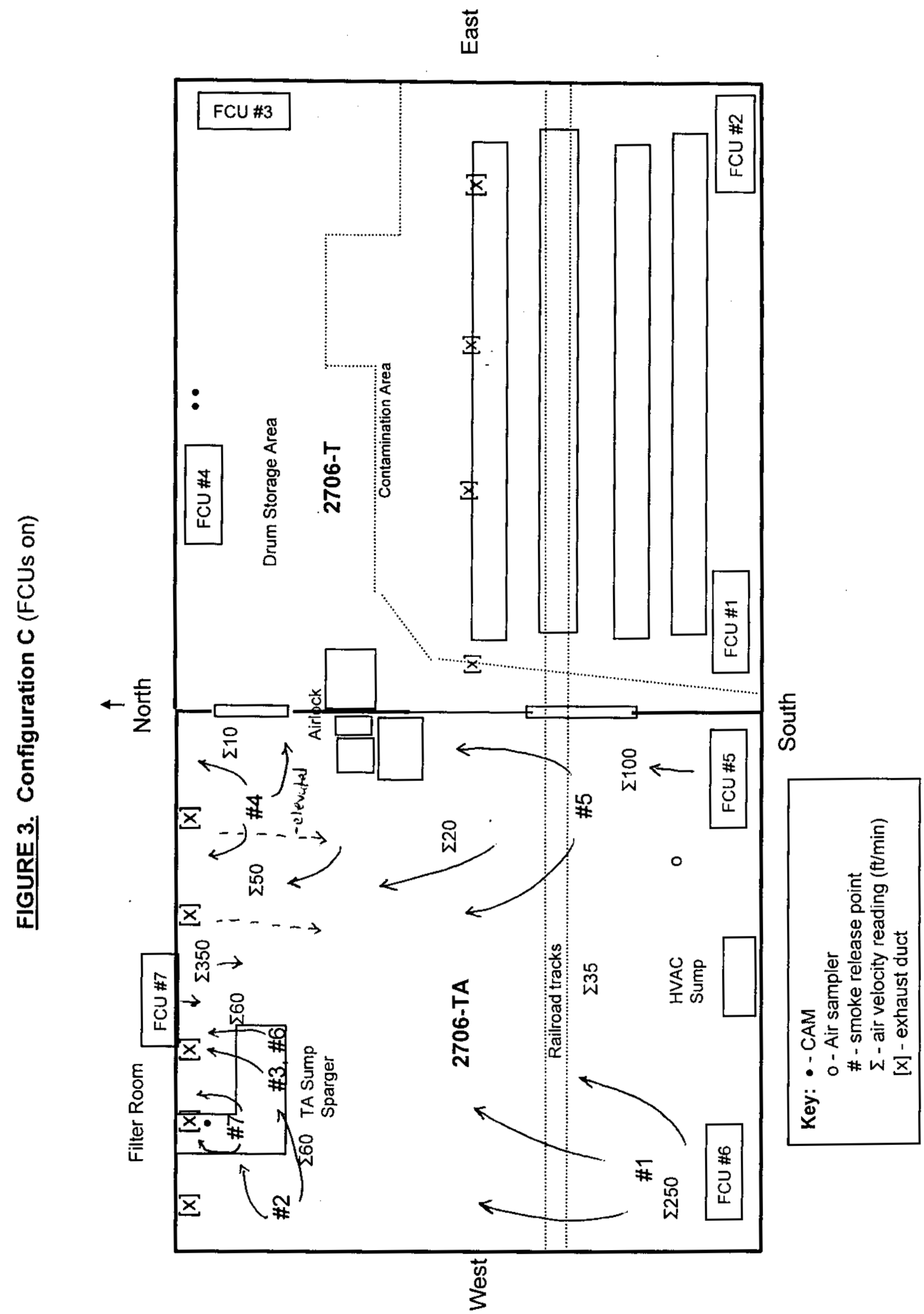


FIGURE 4. Configuration D (FCUs off)

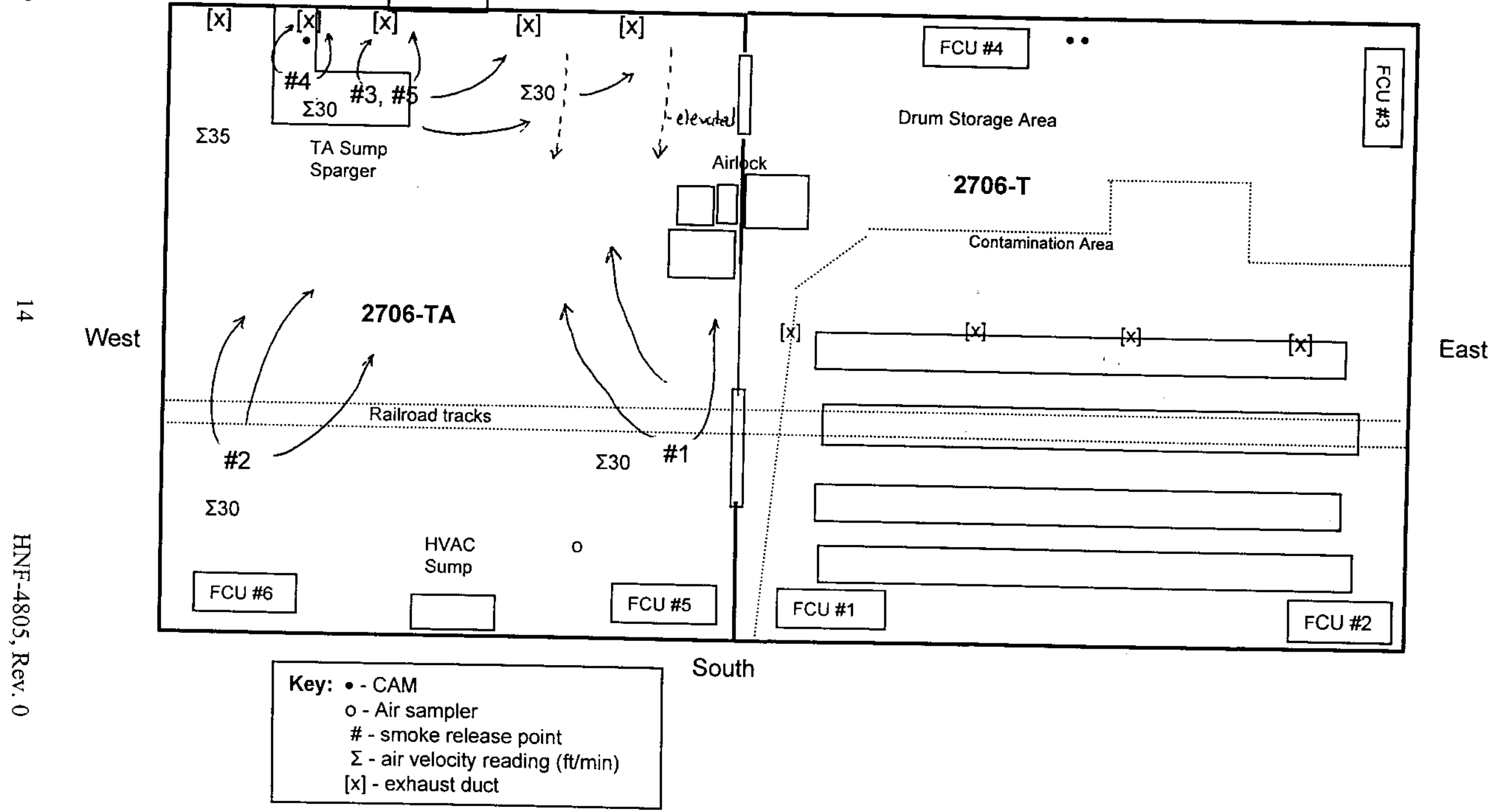


FIGURE 5. Configuration E (FCUs on, doors open)

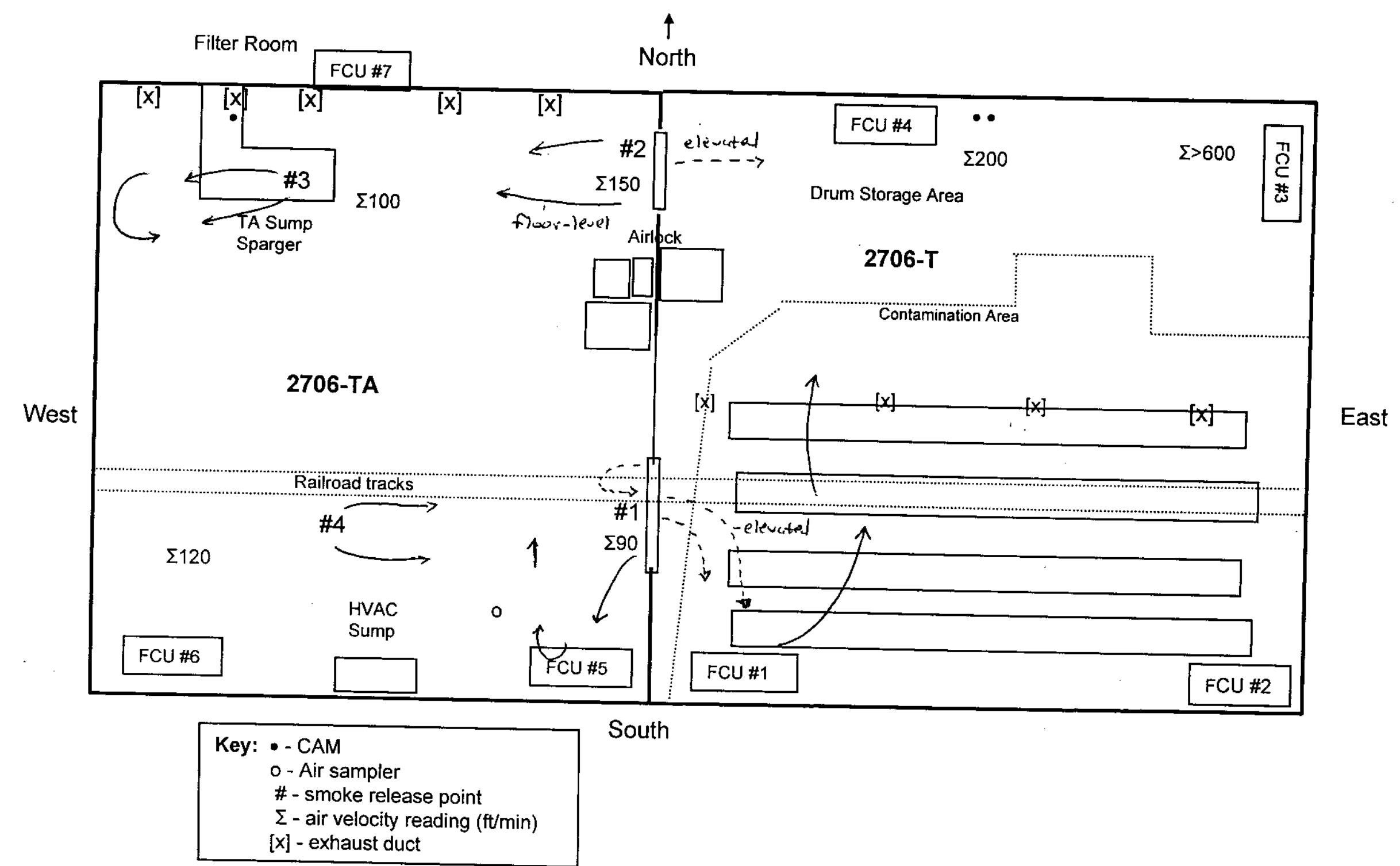


FIGURE 6. Configuration F (FCUs off, doors open)

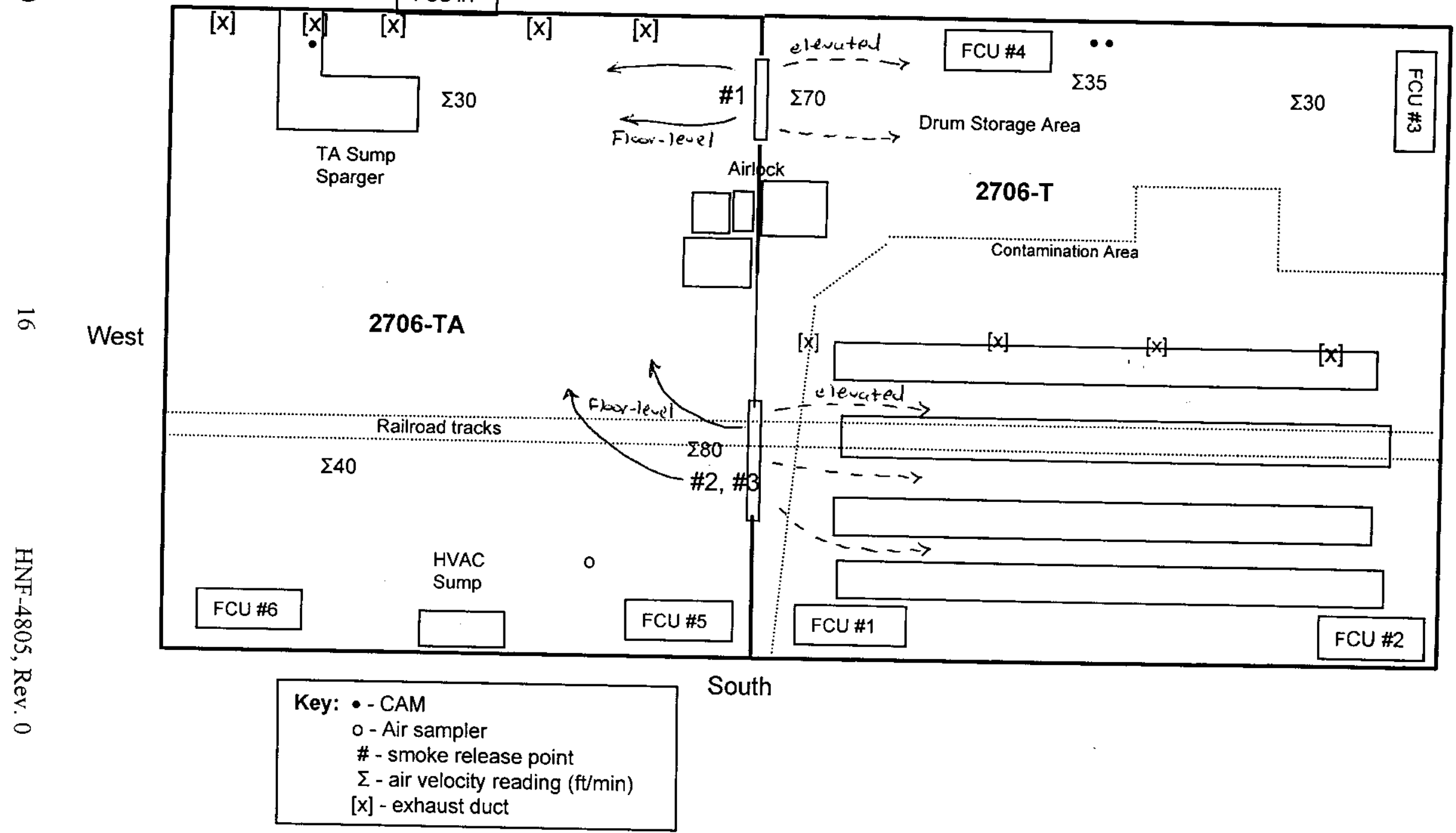




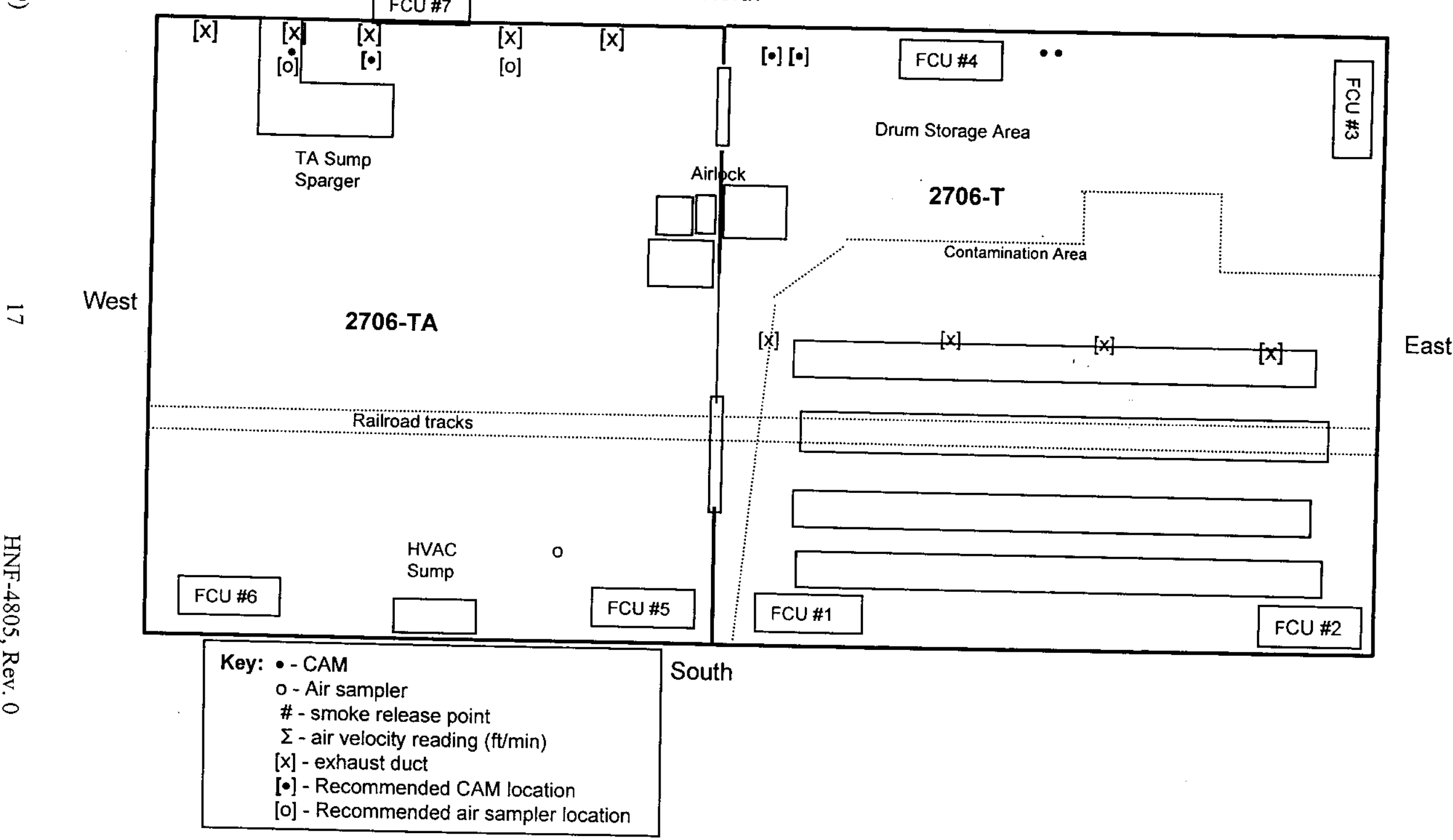

